\title{
Arduino Based Traffic Monitoring and Controlling System
}

\author{
L Srinivas $^{1}$ | J Bhavani $^{1} \mid$ K Janakiram $^{1}$ | M Rupasri ${ }^{1}$ | A B Chandrika ${ }^{1}$ \\ ${ }^{1}$ Department of ECE, VSM College of Engineering, Ramachandrapuram, AP, India.
}

To Cite this Article

L Srinivas, J Bhavani, K Janakiram, M Rupasri and A B Chandrika, "Arduino Based Traffic Monitoring and Controlling System", International Journal for Modern Trends in Science and Technology, Vol. 06, Issue 06, June 2020, pp.:104-107; https://doi.org/10.46501/IJMTST060622

\section{Article Info}

Received on 03-May-2020, Revised on 02-June-2020, Accepted on 07-June-2020, Published on 13-June-2020.

\section{ABSTRACT}

Nowadays, controlling the traffic becomes major issue because of rapid increase in automobiles and also because of large time delays between traffic lights.to optimise this problem we have made a frame work for an intelligent traffic control system. Sometimes higher traffic density at one side of the junction demands longer green time as compared to standard allotment time we, therefore propose here a mechanism in which the time period of green light and red light is assigned on the basis of the density of the traffic present at that time. Once the density is calculated, the glowing time of a green light is assigned by the help of microcontroller(Arduino). The sensors which are present on sides of the roads will detect the presence of the vehicles and sends the information to the microcontroller where it will decide how long a flank will be open or when to change over the signal light. This project explains you how to control the traffic based on density. In this system, we will use IR sensors to measure the traffic density. We have to arrange one IR sensor for each road, these sensors always sense the traffic on that particular road. All these sensors are interfaced to the microcontroller. Based on these sensors, controller detects the traffic and controls the traffic system.

KEYWORDS: IR sensors, microcontroller

Copyright (C) 2014-2020 International Journal for Modern Trends in Science and Technology

DOI: https://doi.org/10.46501/IJMTST060622

\section{INTRODUCTION}

In modern life we have to face many problems one of which is traffic congestion becoming more serious day after day. It is said that the high volume of vehicles, the inadequate infrastructure and the irrational distribution of the development are main reasons for increasing traffic jam. The major cause leading to traffic congestion is the high number of vehicle which was caused by the population and the development of economy. Traffic congestion is a condition on road networks that occurs as use increases, and is characterized by slower speeds, longer trip times, and increased vehicular queuing. The most common example is the physical use of roads by vehicles. When traffic demandidgreat enough that the interaction between vehicles slows the speed of the traffic stream these results in some congestion. As demand approaches the capacity of a road (or of the intersections along the road), extreme traffic congestion sets in. When vehicles are fully stopped for periods of time, this is colloquially known as traffic jam or traffic snarl-up. Traffic congestion can lead to drivers becoming frustrated and engaging in road rage. To solve the problem we are designing a framework for a dynamic and automatic traffic light control system and developed a simulation model with codes in to help build the system on hardware.Generally,each 
traffic light on a intersection is assigned a constant green signal time.It is possible to propose dynamic time-based coordination schemes where the green signal time of the traffic lights is assigned based on the present conditions of traffic.The intelligent work which is done by traffic inspector will be perfectly done by the microcontroller in the circuit with the help of sensors and the program which is coded to the microcontroller.

\section{BLOCK Diagram \&HARDWARE COMPONENTS}

\section{A. Block Diagram:}

An Arduino uno microcontroller has both digital pins and analogue pins. A0 to A5 are analogue pins and 16 digital pins are present. Here in this project we use both analogue and digital pins.IR sensors has three pins. They are ground,output, $5 \mathrm{v}$ power supply.Ground is given common in a breadboard and power supply is connected to $5 \mathrm{v}$ pin in Arduino uno board.Output pin is connected to one of the anlogue pins according to our program.

Here we use LEDs as traffic lights. Which has 2 pins anode and cathode anode is considered as positive and cathode is considered as negative. Now positive is connected to power supply of $5 \mathrm{v}$ in breadboard and negative should be grounded.These are the connections of Arduino based traffic control system.

We use bread board for connections. In these we short all the ground pins. And also short all the power supply pins. These two pins are connected to ground and power supply to microcontroller(Arduino).

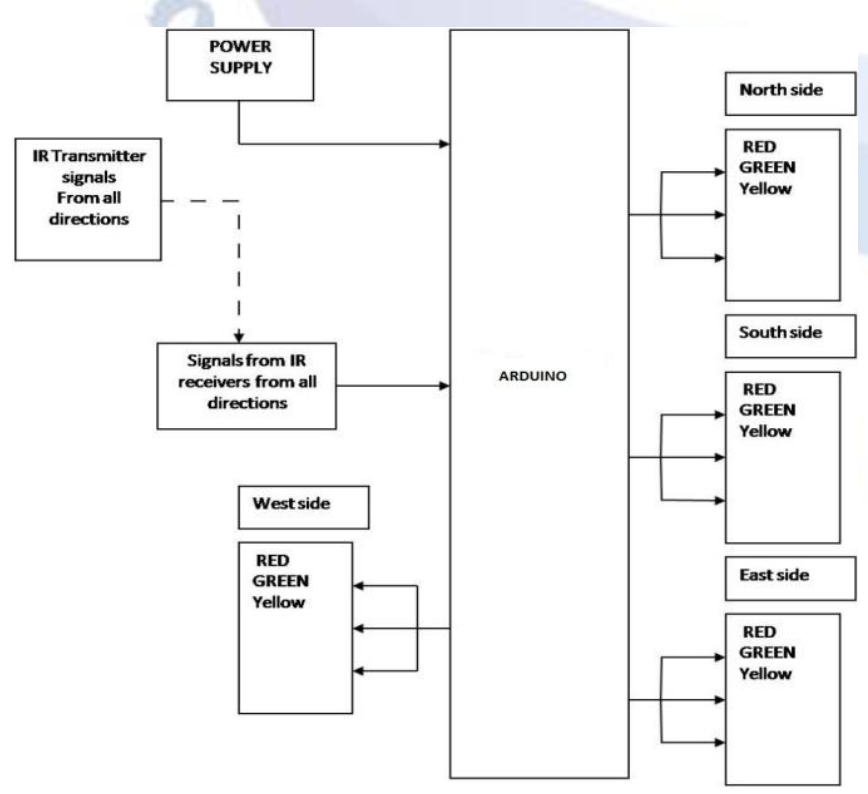

Fig: Block Diagram

\section{B. Hardware Components:}

Arduinoboard:

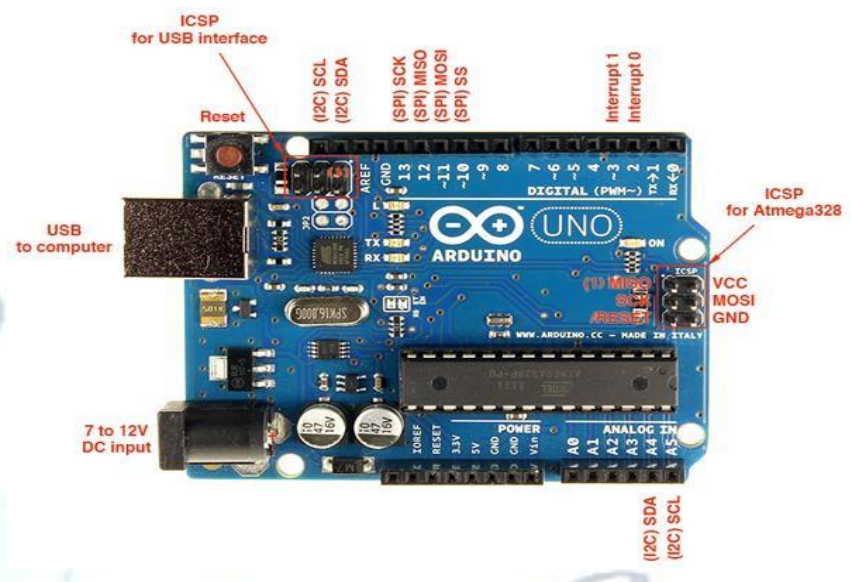

Fig: Arduino board

Arduino board is considered as the brain of the project.It takes input from the IR sensor and according to the input it gives output through LEDS.It controls the total system.In our project we use Arduino uno 328 microcontroller.

The Arduino uno is a microcontroller board based on the AT mega328. It has 14 digital i/o pins(of which 6 can be used as PWM outputs) 6 analog inputs, a $16 \mathrm{MHZ}$ ceramic resonator, a USB connection, a power jack, an ICSP header, and a reset button. It contains everything needed to support the microcontroller, simply connect it to a computer with a USB cable or power it with a AC-DC adapter or battery to get started.

\section{IR Sensor:}

IR sensor is used to detect an object placed in front of it.It has both transmitter and receiver.IR transmitter is used to transmit a light rays and if any object is detected in between that light that information is sent into the IR receiver.And this output is given to the microcontroller.

An infrared sensor emits and/or detects infrared radiation to sense its surroundings. The basic concept of an infrared sensor which is used as obstacle detector is to transmit an infrared signal, this infrared signal bounces from the surface of an object and the signal is received at the infrared receiver. 


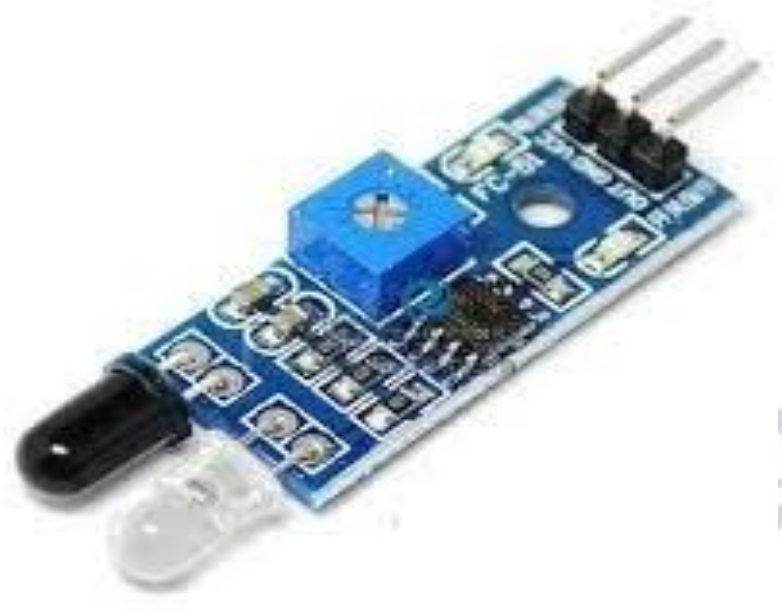

Fig:IR Sensor

\section{LEDs:}

In this project we use LEDs for output as traffic lights. An LED is a light emitting diode is a semiconductor device that emits light due to electroluminescence effect. An LED is basically a PN junction diode, which emits light when forward biased.

In LEDs we have anode and cathode anode is given to power supply and cathode is grounded.based on the output given by the IR sensors to the microcontroller the LEDs gets on in this project.
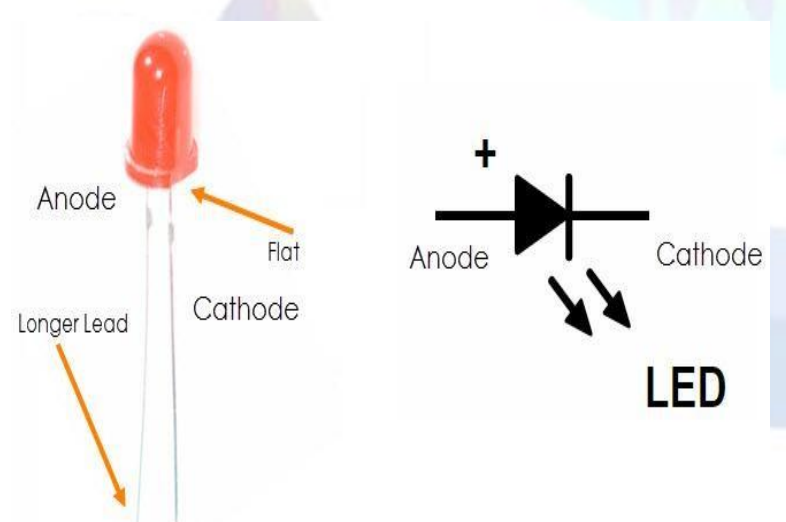

Fig:LEDs

\section{WORKING}

The working of the project is divided into three steps.If there is traffic at all the signals, then the system will work normally by controlling the signals one by one.If there is no traffic near a signal, then the system will skip tis signal and will move on the next one.For example, if there is no vehicle at signal 2,3 and currently the system is allowing vehicles at the signal 1 to pass .Then after signal 1 , the system will move on to signal 4 skipping 2 and 3 .If there is no traffic at all the 4 signals ,system will stop at the current signal and will only move on the next signal if there will be traffic at any other signal.Here the input is taken by using IR sensors at this input is given to the Arduino microcontroller and the output is seen in LEDs.

\section{Applications \& Conclusion}

\section{A. Applications:}

1. The project is mainly used in the control of traffic signals in metropolitan cities to provide uniform distribution of traffic.

\section{B. Conclusion:}

The project is very well used in where the traffic signals is kept and many other places where we need to fulfil the need of the automation. In this project we have studied the optimization of the traffic light controller in a city using IR sensors shows the complete circuit diagram of Arduino board. By using this system configuration we tries to reduce the possibilities of traffic jams, caused by traffic lights, to an extent and we have successfully get the results.

We will implement this system for traffic controlling in a 4 lane junction. We will update this system with when a pedestrian try to cross the road during green signal it will turn on a alarm and warn the pedestrian and traffic police. And we will try to update this when a vehicle try to move even during red signal it will turn an alarm to the driver of the vehicle and traffic.

\section{OUTPUT:}

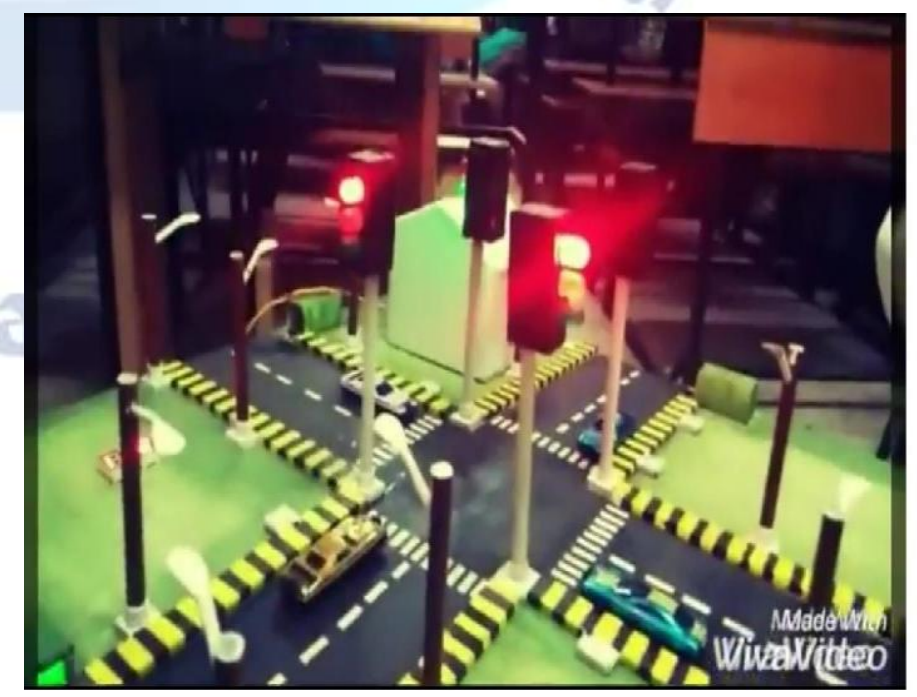

Fig:working module 


\section{REFERENCES}

[1] M. A.A. Parkhi, Mr. A.A. Peshattiwar, Mr. K.G. Pande "Intelligent Traffic System Using Vehicle Density". Yeshwantrao Chavan College of Engg., Nagpur. International Journal of Electrical and Electronic Engoneers, 2016.

[2] Bilal Ghazal, Khaled ElKhatib "Smart Traffic Light Control System”. Conference Paper- April 2016.

[3] Dinesh Rotake, Prof. Swapnil Karmore "Intelligent Traffic Signal Control System Using Embedded System”. G.H Raisoni College of Engineering, Nagpur. Innovative Systems Design and Engineering, 2012.

[4] Malik Tubaishatr, Ti Shang and Hongchi Shi "Adaptive Traffic Light Control with Wireless Sensor Networks". Article- January 2007.

[5] Nang Hom Kham, ChawMyat New "Implementation of Modern Traffic Light Control System". Department of Electronic Engineering, Mandalay Technological University, Myanmar. International Journal of Scientific and Research Publications, June 2014.

[6] Intelligent Traffic Control System Using Arduino UNO by J. Jasmine, M. Deva Priya, G. Ram Swathi, P. Nachiyar.

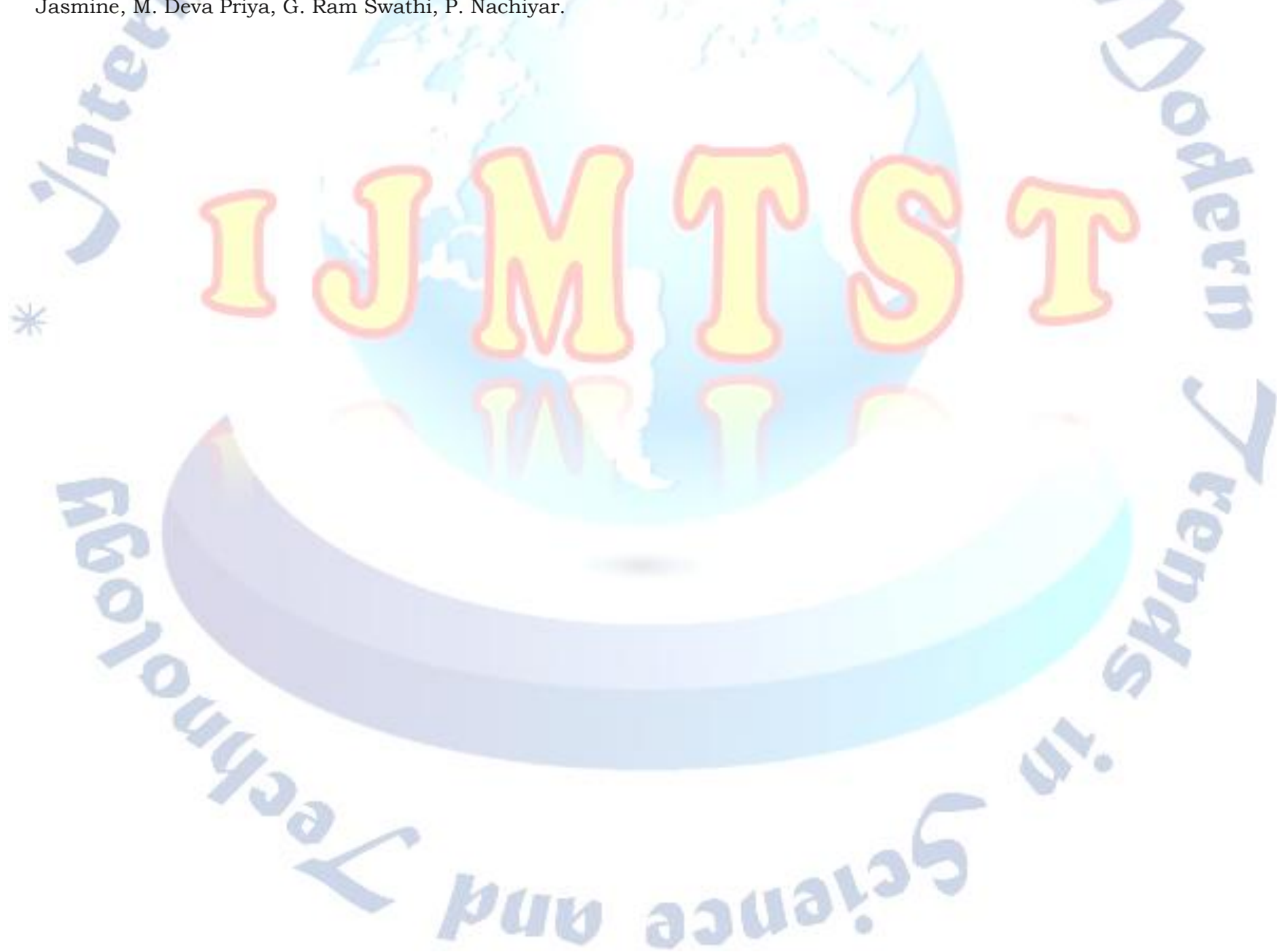

